\title{
Periotest Values of Implants Placed in Sockets Augmented with Calcium Phosphosilicate Putty Graft: A Comparative Analysis against Implants Placed in Naturally Healed Sockets
}

\author{
${ }^{1}$ Lanka Mahesh, ${ }^{2}$ TV Narayan, ${ }^{3}$ Georgios Kostakis, ${ }^{4}$ Sagrika Shukla
}

\begin{abstract}
Aim: To measure implant stability using periotest values of implants placed in sockets augmented with calcium phosphosilicate putty (CPS Putty) as compared with implant stability in naturally healed sockets.
\end{abstract}

\begin{abstract}
Materials and methods: Twenty two sockets were implanted with CPS Putty immediately after extraction. The sockets were re-entered after a healing period at 5 to 6 months (average 5.3 months) for implant placement. Periotest values were recorded during implant insertion to assess primary stability. These were compared with the Periotest values of 26 implants placed in 22 patients, with naturally healed sockets.
\end{abstract}

Result: Periotest values were significantly lower in the grafted group, indicating better implant stability in sites grafted with CPS putty.

Conclusion: Implant stability seems to be significantly higher in sockets augmented using CPS putty when compared to nongrafted sites. This suggests that socket grafting with CPS putty may enhance the quality of available bone for implantation.

Keywords: Implant stability, Periotest, CPS putty.

How to cite this article: Mahesh L, Narayan TV, Kostakis G, Shukla S. Periotest Values of Implants Placed in Sockets Augmented with Calcium Phosphosilicate Putty Graft: A Comparative Analysis against Implants Placed in Naturally Healed Sockets. J Contemp Dent Pract 2014;15(2):181-185.

Source of support: Nil

Conflict of interest: None

\section{INTRODUCTION}

For successful esthetic and functional integrity of an implant, it must osseointegrate and have maximum bone implant

\footnotetext{
${ }^{1}$ Private Practice, The Dental Center, Panshila Park, New Delhi, India

${ }^{2}$ Private Practice, Bengaluru, Karnataka, India

${ }^{3}$ Resident, Department of Periodontology, University of Minnesota, Minneapolis, MN, USA

${ }^{4}$ Private Practice, New Delhi, India

Corresponding Author: Lanka Mahesh, Private Practice, The Dental Center S382 Panshila Park, New Delhi 110017, India Phone: +91 98112-68584, e-mail: drlanka.mahesh@gmail.com
}

contact (BIC). ${ }^{1}$ Research has shown that bone in contact with the implant 1 year after its insertion was superior to that found at 6 months, and the latter to that found at 3 months. ${ }^{2}$ However, clinicians load an implant after 4 to 6 months of an implant insertion, taking advantage of the bone mass generated by the healing process. ${ }^{3}$

For successful osseointegration and maximum BIC, good quality and volume of bone is necessary, which can be studied by taking histological sections. However, when histological examination is not possible, digital testing or radiography is used for testing implant stability. Various methods have been developed to assess primary and secondary stability, such as electronically-controlled mechanical tapping devices (MTD), ${ }^{4}$ electronic and magnetic resonance frequency analysis devices (RFAD), ${ }^{5}$ cutting torque resistance analysis, reverse torque test, modal analysis, percussion test, impact hammer test, and pulsed oscillation waveform. ${ }^{6}$ Resonance frequency analysis (RFA) and MTD are the two most widely used methods to check implant stability.

Resonance frequency analysis uses two machines, Osstell (Osstel AB, Sweden) and Implomates (Medizintechnik Gulden e.K, Germany). Osstell was introduced by Meredith ${ }^{7}$ and is based on continual excitation of the implant through dynamic vibration analysis. It makes use of a transducer connected to an implant, which is exited over a range of sound frequencies with subsequent measurement of vibratory oscillation of the implant. This technique causes the implant to vibrate while at the same time analyses implant motion, and provides information as an implant stability quotient on a scale of 1 to 100 .

MTD- Periotest, was developed to measure the damping characteristics of natural teeth and has been used to evaluate implant stability. ${ }^{8}$ It was developed by Schulte et $\mathrm{al}^{9}$ and D'hoedt et al. ${ }^{10}$ This apparatus is based on a metal rod of $8 \mathrm{gm}$, which is displaced in a backward and foreward movement at a given speed. When the rod taps an object, it deaccelerates. The contact time per impact between the rod and the implant lies within the range of milliseconds and represents the measured parameter based on a scale of values ranging from -8 to +50 . These figures are called periotest 
values (PTV). The more the negative the range of value is, the more stable the implant, because it is surrounded by dense bone. On the other hand, if PT is positive, it means it has more capacity to absorb impact and therefore, is surrounded by fibrous tissue. ${ }^{3}$

PTV depends upon viscoelastic characteristics of the periodontium. During the measurement, the sleeve of the handpiece is kept at a distance of $0.5 \mathrm{~mm}-2.5 \mathrm{~mm}$, horizontal at the right angle to the center of the facial anatomic coronal surface of the abutment. The Periotest is capable of providing valuable information concerning favorable or unfavorble changes in the bone implant interface, and also information regarding when an implant can be loaded. ${ }^{11}$

The MTD has been considered a nondestructive stability-measuring device. ${ }^{12,13}$ Aparicio et al reported no complication in measuring secondary stability in 1,182 implants using MTD; its value was advocated as one initial criterion of implant success. ${ }^{14}$ However, its use on implants is contraindicated during the first 2 to 3 months of healing. ${ }^{15}$ According to Seong et al, ${ }^{15}$ repeated MTD measurements damage bone-implant interface at the time of implant placement. However, according to Mesa et $\mathrm{a}^{16}$ and Noguerol et $\mathrm{al}^{13}$ no complications were reported when measurements were done using MTD at first and second stage surgeries. Another study with sample size of 2,900 reported implant success based on PTV. ${ }^{18}$ In an animal study by Dilek et al, ${ }^{19}$ initial implant-stability measurements using the MTD in immediately-loaded implants were performed, without any related complications. The advantage of Periotest is that longterm data has shown that it can be an objective clinical measurement of the stability of bone-implant contact measurement. It precisely reflects the condition of BIC.

The success of an implant based on Periotest values largely depends upon type of bone available for an implant

Table 1: Age distribution

\begin{tabular}{lllll}
\hline \multirow{2}{*}{ Age in years } & \multicolumn{2}{c}{ Group A } & \multicolumn{2}{c}{ Group B } \\
\cline { 2 - 5 } & No & $\%$ & No & $\%$ \\
\hline $21-30$ & 5 & 22.7 & 7 & 31.8 \\
$31-40$ & 6 & 27.3 & 9 & 40.9 \\
$41-50$ & 6 & 27.3 & 2 & 9.1 \\
$51-60$ & 5 & 22.7 & 4 & 18.2 \\
\hline Total & 22 & 100.0 & 22 & 100.0 \\
\hline Mean \pm SD & $40.64 \pm 12.12$ & $37.59 \pm 9.93$ \\
\hline
\end{tabular}

Samples are age matched with $p=0.367$

Table 2: Gender distribution of patients studied

\begin{tabular}{lllll}
\hline \multirow{2}{*}{ Gender } & \multicolumn{2}{c}{ Group A } & \multicolumn{2}{c}{ Group B } \\
\cline { 2 - 5 } & No & $\%$ & No & $\%$ \\
\hline Male & 13 & 59.1 & 11 & 50.0 \\
Female & 9 & 40.9 & 11 & 50.0 \\
\hline Total & 22 & 100.0 & 22 & 100.0 \\
\hline
\end{tabular}

Samples are gender matched with $\mathrm{P}=0.753$ to osseointegrate and have maximum BIC. If bone is of poor quality and less volume, it can be improved through various graft materials available. CPS Putty (NovaBone Dental Putty, NovaBone Products, Alachua, FL) is an osteoconductive bioactive graft material which is a pre-mixed composite of bioactive calcium phosfate silica particulate and a synthetic absorbable binder. The bio-active particulate is composed solely of elements that exist naturally in bone, such as $\mathrm{Ca}$, $\mathrm{P}, \mathrm{Na}, \mathrm{Si}$ and $\mathrm{O}$, with the binder being a combination of polyethylene glycol and glycerine. ${ }^{20}$

CPS putty stimulates osteoblast recruitment, proliferation and differentiation at the defect site and increases rate of bone formation, not just at the edges but throughout the defect. It exhibits a higher rate of particle resorption and does not generate bone in nonosseous sites. Results of a study on the effect of silica-containing calcium phosphate particles on human osteoblasts in vitro demonstrated that this new bioactive glass enhanced the proliferation response of osteoblasts compared with osteoblasts alone and did not induce stimulation of proinflammatory markers iNOS and IL-1 beta. ${ }^{21}$

\section{MATERIALS AND METHODS}

Patients selected for this study were healthy, without any medical condition. Consent for the same was taken from the patients. Age distributions are depicted in Table 1 and Graph 1, and gender distributions are represented in Table 2 and Graph 2. Patients were divided into two groups. Group A consisted of 22 patients with naturally healed sockets, where 26 Bio-Horizons internal implants were placed and PTV was recorded. Group B consisted of 22 patients where CPS Putty was placed for socket augmentation in single extraction sockets. The site distribution is represented in (Table 3 and Graph 3). Six months after grafting, 22 Bio-Horizons internal Implants were placed and PTV measured.

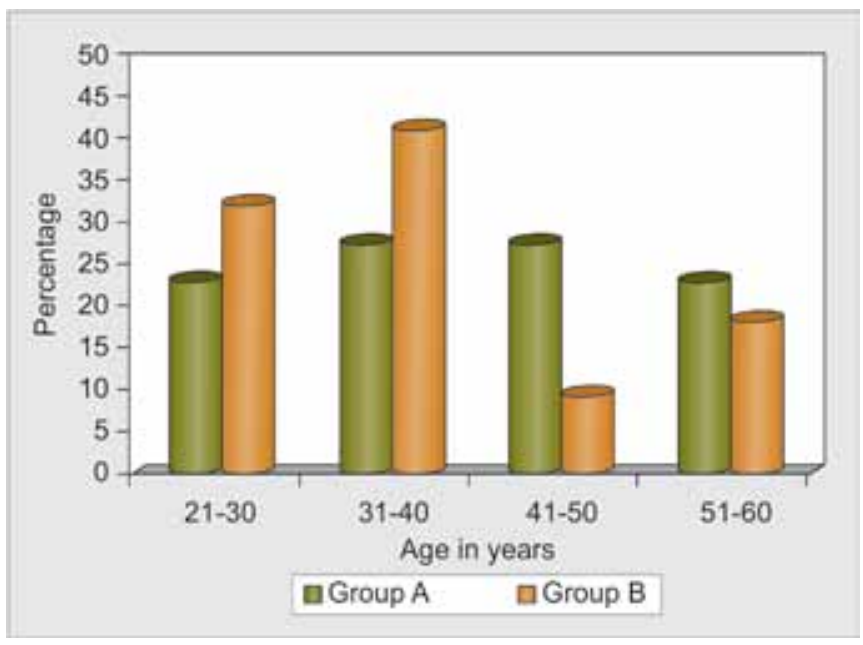

Graph 1: Age distribution 

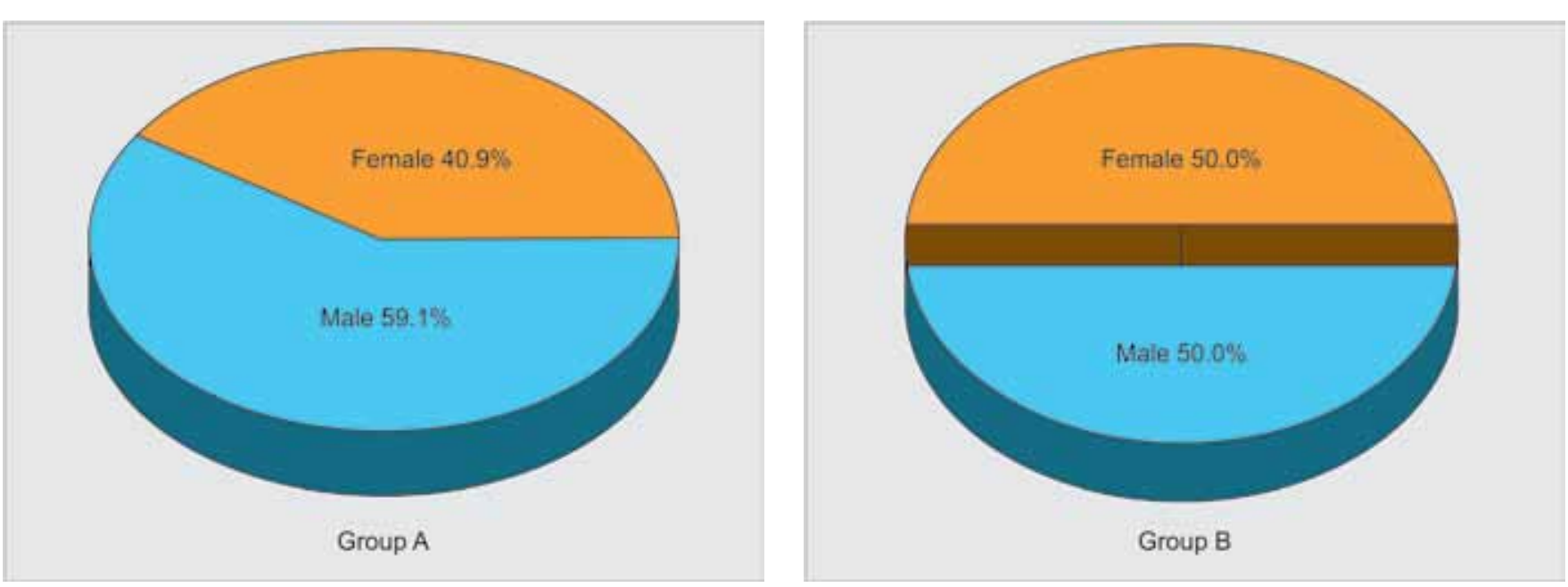

Graph 2: Gender distribution of patients studied

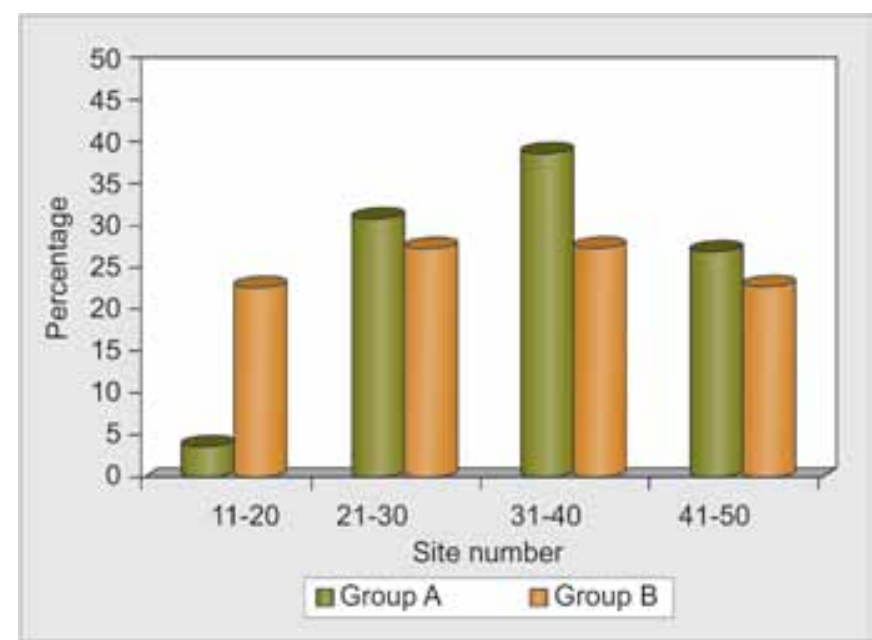

Graph 3: Site distribution

\section{STATISTICAL METHODS}

Descriptive statistical analysis has been carried out in the present study. Results on continuous measurements are presented on mean $\pm \mathrm{SD}$ (min-max) and results on categorical measurements are presented in Number (\%). Significance is assessed at $5 \%$ level of significance. The following assumptions on data is made, Assumptions: (1) dependent variables should be normally distributed, (2) samples drawn from the population should be random, Cases of the samples should be independent.

Student t-test (two-tailed, independent) has been used to find the significance of study parameters on continuous scale between two groups intergroup analysis) on metric parameters. Levene's test for homogeneity of variance has been performed to assess the homogeneity of variance. The Statistical software: SAS 9.2, SPSS 15.0, Stata 10.1, MedCalc 9.0.1 Systat 12.0 and R environment ver.2.11.1 were used for the analysis of the data. Microsoft word and Excel were used to generate graphs, tables, etc.
Table 3: Site distribution

\begin{tabular}{lllll}
\hline Site number & \multicolumn{2}{c}{ Group A } & \multicolumn{2}{c}{ Group B } \\
\cline { 2 - 5 } & No & $\%$ & No & $\%$ \\
\hline $11-18$ & 1 & 3.8 & 5 & 22.7 \\
$21-28$ & 8 & 30.8 & 6 & 27.3 \\
$31-38$ & 10 & 38.5 & 6 & 27.3 \\
$41-48$ & 7 & 26.9 & 5 & 22.7 \\
\hline Total & 26 & 100.0 & 22 & 100.0 \\
\hline
\end{tabular}

Table 4: Comparison of PTV in two groups studied

\begin{tabular}{lll}
\hline PTV & \multicolumn{1}{c}{ Group $A$} & Group B \\
\hline Min-Max & -7.30 to -6.10 & -7.20 to -6.70 \\
Mean \pm SD & $-6.81 \pm 0.32$ & $-6.97 \pm 0.14$ \\
95\%Cl & -6.94 to -6.68 & -7.03 to -6.90 \\
Inference & PTV values are significantly high in group \\
& A $(-6.81)$ compared to group B (-6.97) with \\
& $\mathrm{p}=0.040^{*}$ & \\
\hline
\end{tabular}

Suggestive significance ( $p$-value: $0.05<p<0.10$ );

Moderately significant ( $p$-value: $0.01<p \leq 0.05$ );

Strongly significant $(p$-value $: p \leq 0.01)$

\section{RESULTS}

In group A, a total of 26 implants were placed in 22 patients with periotest values ranging from -7.3 to -6.1 with a mean of -6.81 . In group B, the periotest values ranged from -7.2 to -6.7 with a mean of -6.97 . There was moderately significant difference in the implant stability between the two groups, with group B exhibiting higher stability (Table 4 and Graph 4).

\section{DISCUSSION}

An implant must be stable to serve its functional and esthetic purpose, for which BIC is essential. Research has shown that minimum BIC must reach $50 \%$ for successful integration of endosseous implants. ${ }^{22,23} \mathrm{BIC}$ is dependent largely on bone quality. ${ }^{22}$ 


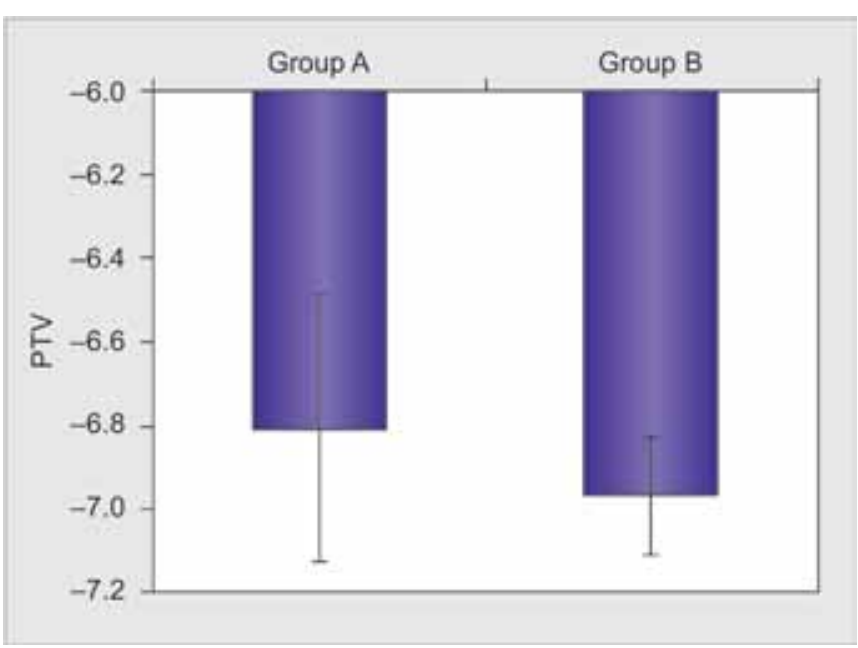

Graph 4: Comparison of PTV in two groups

PTV has been one of the methods of determining implant stability and by default a measure of BIC. Truhlar, Morris and Ochi in a comprehensive longitudinal study on the stability of Bone-Implant complexes using Periotest values drew up a few pertinent conclusions namely that (1) PTV is influenced by bone quality, (2) PTVs at second stage is the best estimate of the clinically acceptable PTV for a given Bone-Implant complex and (3) A consistent shift toward a positive PTV is a cause for concern with the given BIC and should be viewed as a possible deterioration of the same. ${ }^{18}$ Numerous other studies extol the value of Periotest in assessing implant stability and the integrity of the BIC particularly at the time of uncovering. ${ }^{17}$

We examined the initial stability of implants placed in grafted sites as opposed to naturally healed sites using the more objective method of periotest values as opposed to the mere measure of insertion torque and found the grafted sites to record marginally better PTVs than the naturally healed sites, implying an improvement in the quality of bone.

To the best of our knowledge, this is the first such descriptive study on the initial stability of implants in grafted sites vs naturally healed sites.

\section{CONCLUSION}

Socket grafting is an accepted method of maintaining bone volume for optimal implant placement. A serendipitous side effect of socket grafting with materials like CPS putty seems to be the improvement in quality of the regenerated bone. This finding raises the possibility of bio-modification of already healed sites where bone quality is too poor for predictable and successful implant placement, by creating an artificial socket and grafting with CPS putty and re-entering to place the implant.

\section{ACKNOWLEDGMENT}

Dr KP Suresh, Scientist (Biostatistics) National Institute of Animal Nutrition and Physiology, Bengaluru, 560030.

\section{REFERENCES}

1. Oh TJ, Yoon J, Meraw SJ, Giannobile WV, Wang HL, Healing and osseointegration of submerged microtextured oral implants. Clin Oral Implants Res 2003 Oct;14(5):643-650.

2. Froum SJ, Simon H, Cho SC, Elian N, Rohrer MD, Tarnow DP. Histologic evaluation of bone-implant contact of immediately loaded transitional implants after 6 to 27 months - Int J Orla Maxillofac Implants 2005;20:54-60.

3. Aparicio C. The use of the periotest values as the initial criteria of an implant: 8 - year report. Int J Periodontal Rest Dent 1997; 17:151-161.

4. Olive' J, Aparicio C. Periotest method as a measure of osseointegrated oral implant stability. Int J Oral Maxillofac Implants 1990;5:390-400.

5. Meredith N, Alleyne D, Cawley P. Quantitative determination of the stability of the implant-tissue interface using resonance frequency analysis. Clin Oral Implants Res 1996;7:261-267.

6. Atsumi M, Park SH, Wang H. Methods used to assess implant stability: current status. Int J Oral Maxillofac Implants 2007;22:743-754.

7. Meredith N, Rasmusson L, Alleyne D. Mapping implant stability by resonance frequency analysis. Med Sci Res 1996;24:191-193.

8. Cehreli MC, Karasoy D, Akca K, Eckert SE. Meta-analysis of methods used to assess implant stability. Int J Oral Maxillofac Implants 2009;24:1015-1032.

9. Shulte W, D'Hoedt B, Lukas D, muhibradt L, Scholz F, Bretschi J et al. Periotest-neues messverfahren der function des paradontiums. Zahnarzti Mitt 1983;73:1229-1240.

10. D'Hoedt B, Lukas D, Mühlbradt L, Scholz F, Schulte W, Quante F, Topkaya A. Periotest research and clinical trials. dtsch zahnarztl z 1985;40:113-125.

11. Morris HE, Ochi S, Crum P, Orenstein I, Plezia R. Bone density: Its influence on implant stability after uncovering. J Oral Implantol 2003;29(6):263-269.

12. Meredith N. Assessment of implant stability as a prognostic determinant. Int J Prosthodont 1998;11:491-501.

13. Noguerol B, Munoz R, Mesa F, de Dios Luna J, O’Valle F. Early implant failure. Prognostic capacity of Periotest: Retrospective study of a large sample. Clin Oral Implants Res 2006;17:459464.

14. Aparicio C. The use of the Periotest value as the initial success criteria of an implant: 8-year report. Int J Periodontics Restorative Dent 1997;17:150-161.

15. Seong JW, Conrad HJ, Hinrichs JE. Potential damage to boneimplant interface when measuring initial implant stability. J Periodontol 2009;80:1868-1874.

16. Mesa F, Munõz R, Noguerol B, de Dios Luna J, Galindo P, O'Valle F. Multivariate study of factors influencing primary dental implant stability. Clin Oral Implants Res 2008;19: 196-200

17. Walker L, Morris HF, Ochi S. Periotest values of dental implants in the first 2 years after second stage surgery: DICRG interim 
report no. 8. Dental implant clinical research group. Implant Dent 1997;6:207-212.

18. Truhlar RS, Morris HF, Ochi S. Stability of the bone-implant complex. Results of longitudinal testing to 60 months with the periotest devices on endosseous dental implants. Ann Periodontal 2000;5:42-55.

19. Dilek O, Tezulas E, Dincel M. Required minimum primary stability and torque values for immediate loading of mini dental implants: an experimental study in nonviable bovine femoral bone. Oral Surg Oral Med Oral Pathol Oral Radiol Endod 2008;105:e20-e27.

20. Elshahat A. correction of craniofacial skeleton contour defects using bioactive glass particles. J Plast Reconstr Surg July 2006; 30(2):113-119.
21. In publication - Comparative evaluation of an alloplastic graft (NovaBone) and xenograft (Bio-oss) in immediate post-extraction socket augmentation: a histological pilot study.

22. Trisi P, Lazzara R, Rebaudi A, Rao W, Testori T, Porter SS. Boneimplant contact on machined and dual acid-etched surface after 2 months of healing in human maxilla. J Periodontal 2003; 74:945-956.

23. Albrektsson T, Johansson C. Quantified bone tissue reactions to various metallic materials with reference to the so-called osseointegration concept. In: davies JE, editor. The bone-biomaterial interface. Toronto: University of Toronto press; 1991: 357-363. 